\title{
Analyses of the genome and transcriptomes of endemic Baikal sponges (Lubomirskildae)
}

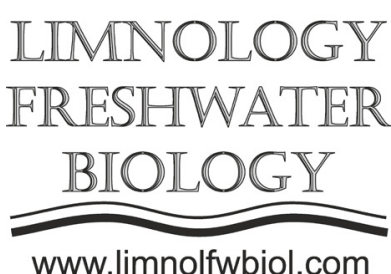

\author{
Itskovich V.B. ${ }^{1 *}$, Riesgo A. ${ }^{2,3}$, Kenny N.J. ${ }^{2,4}$ \\ ${ }^{1}$ Limnological Institute, Siberian Branch of the Russian Academy of Sciences, Ulan-Batorskaya Str., 3, Irkutsk, 664033, Russia \\ ${ }^{2}$ Life Sciences, The Natural History Museum, Cromwell Rd, London SW7 5BD, UK \\ ${ }^{3}$ Department of Biodiversity and Evolutionary Biology, The National Museum of Natural Sciences, Madrid, Spain \\ ${ }^{4}$ Present Address: Faculty of Health and Life Sciences, Oxford Brookes, Oxford OX3 OBP, UK
}

\begin{abstract}
The fauna of endemic Baikal sponges is very diverse, however, the systematics of Lubomirskiidae is contradictory when morphological and molecular data. The development of a taxonomy for Baikal sponges is very important for their conservation. The recently recorded massive disease outbreak and death of Baikal sponges has raised monitoring issues. In order to study the evolution of endemic Baikalian sponges on genomic level we analyzed a draft genome of the Baikal sponge Lubomirskia baikalensis and transcriptomes of three Lubomirskiidae species, obtained using Illumina sequencing. The genome size of Lubomirskia baikalensis (approximately 560 million base pairs) is almost twice that of the closest sequenced outgroup species, Ephydatia muelleri. Given the age of Baikal sponge radiation, these differences have occurred over a relatively short period of time. As Ephydatia is also a freshwater sponge, it is likely that this increase is not due to adaptation to freshwater habitats, but is the result of evolutionary processes related to the sympatric speciation of sponges in Lake Baikal.
\end{abstract}

Keywords: Lake Baikal, sponges, Porifera, transcriptome, genome, evolution, freshwater

One of the fundamental questions in animal evolution is the relationship between genomic sequence and the morphological characteristics of species. Sponges are one of the earliest-diverging metazoan clades, and are at least 580 million years old. Their ancient origin and early split from the animal stem lineage make them an important object of study for understanding the evolution of the metazoan genomes. The first genomic studies of sponges showed that sponges have amazingly complex genomes, both in terms of gene composition and functional repertoire, while a rich gene repertoire existed even before the appearance of real tissues (Hashimshony et al., 2015; Adamska, 2016;). These studies emphasized the importance of gene loss and spatio-temporal changes in the regulation of gene expression in the formation of multicellular genomes and revealed the presence of an extremely diverse gene repertoire in these morphologically simple multicellular organisms (Riesgo et al., 2014).

The fauna of endemic Baikal sponges is very diverse, with 14 species and 2 subspecies presently described in the family Lubomirskiidae (Efremova, 2004). However, the systematics of Lubomirskiidae is contradictory when morphological and molecular data are compared. Current molecular data are insufficient to distinguish all species of Lubomirskiidae and to understand their phylogenetic relationships. The development of a robust taxonomy for Baikal sponges is very important for their conservation. The recently recorded massive disease outbreak and death of Baikal sponges (Timoshkin et al., 2016; Khanaev et al., 2018; Itskovich et al., 2018) has raised issues regarding the monitoring of these species. In order to study the evolution of endemic baikalian sponges on a genomic scale, we have sequenced the draft genome of the Baikal sponge Lubomirskia baikalensis and transcriptomes of three Lubomirskiidae species using Illumina sequencing.

Our results showed that the genome size of Lubomirskia baikalensis (as determined using GenomeScope) is between 558 and 565 million base pairs (Kenny et al., 2019). This is larger than almost all known marine sponge genomes. It also exceeds the size of the genomes of freshwater sponges of the family Spongillidae, ranged in size from 310 to 360 megabases (Jeffery et al., 2013). Among freshwater sponges, the sister taxon to Lubomirskiidae is Ephydatia muelleri (Itskovich et al., 2008). The genome size of the recently sequenced genome of $E$. muelleri is 326 million base pairs (Kenny et al., 2020), and the genome of L. baikalensis is almost twice this size. The Lubomirskiidae colonized Lake Baikal 3.4 Mya, 15 My after the relatively recent radiation of freshwater sponges (Schuster et al., 2018). Given the age of Baikal sponges, these differences in genome have formed over a relatively short period of 
time. As other freshwater sponges have small genomes, an increase in the genome size of $L$. baikalensis cannot be attributed to adaptation to the freshwater environment. The expansion of the L. baikalensis genome is therefore likely due to lineage-specific factors, possibly associated with the sympatric speciation of sponges in Lake Baikal. Data on the structure of the genome and transcriptomes of Baikal sponges obtained in the course of this work are a unique molecular resource for Porifera research. Reconstruction of the phylogeny of Baikal endemic sponges (Lubomirskiidae) based on this data is underway, and will ensure conservation decisions can be made with reference to a robust phylogenetic framework.

\section{Acknowledgment}

The work was supported by basic funding № 0345-2019-0002, by RFBR and DST according to the research project № 19-54-45034 and RFBR № 20-0400868 .

\section{References}

Adamska M. 2016. Sponges as models to study emergence of complex animals. Current Opinion in Genetics \& Development 39: 21-28. DOI: 10.1016/j.gde.2016.05.026

Efremova S.M. 2004. New genus and new species of sponges from family Lubomirskiidae Rezvoj, 1936. In: Timoshkin O.A., Sitnikova T.Ya., Rusinek O.T. (Eds.), Annotirovannyy spisok fauny ozera Baykal i yego vodosbornogo basseyna [Index of animal species inhabiting Lake Baikal and its catchment area]. Novosibirsk, pp. 182-192. (in Russian)

Hashimshony T., Feder M., Levin M. et al. 2015. Spatiotemporal transcriptomics reveals the evolutionary history of the endoderm germ layer. Nature 519(7542): 219-222. DOI: $10.1038 /$ nature13996

Itskovich V.B., Gontcharov A., Masuda Y. et al. 2008. Ribosomal ITS sequences allow resolution of freshwater sponge phylogeny with alignments guided by secondary structure prediction. Journal of Molecular Evolution 67(6): 608-620. DOI: 10.1007/s00239-008-9158-5

Itskovich V.B., Shigarova A.M., Glyzina O.Yu. et al. 2018. Heat shock protein 70 (Hsp70) response to elevated temperatures in the endemic Baikal sponge Lubomirskia baicalensis. Ecological Indicators 88: 1-7. DOI: 10.31951/2658-3518-2019-A-1-172

Jeffery N.W., Jardine C.B., Gregory T.R. 2013. A first exploration of genome size diversity in sponges. Genome 56: 451-456. DOI: 10.1139/gen-2012-0122

Kenny N.J., Plese B., Riesgo A. et al. 2019. Symbiosis, selection, and novelty: freshwater adaptation in the unique sponges of Lake Baikal. Molecular Biology and Evolution 36(11): 2462-2480. DOI: 10.1093/molbev/msz151

Kenny N.J., Warren R.F., Rivera-Vicéns R.E. et al. 2020. Tracing animal genomic evolution with the chromosomal-level assembly of the freshwater sponge Ephydatia muelleri. Nature Communications 11. DOI: 10.1038/s41467-020-17397-w

Khanaev I.V., Kravtsova L.S., Maikova O. et al. 2018. Current state of the sponge fauna (Porifera: Lubomirskiidae) of Lake Baikal: sponge disease and the problem of conservation of diversity. Journal of Great Lakes Research 44(1): 77-85. DOI: 10.1016/j.jglr.2017.10.004

Riesgo A., Farrar N., Windsor P.J. et al. 2014. The analysis of eight transcriptomes from all poriferan classes reveals surprising genetic complexity in sponges. Molecular Biology and Evolution 31(5): 1102-1120. DOI: 10.1093/molbev/ msu057

Schuster A., Vargas S., Knapp I.S. et al. 2018. Divergence times in demosponges (Porifera): first insights from new mitogenomes and the inclusion of fossils in abirth-death clock model. BMC Evolutionary Biology 18(1). DOI: 10.1186/ s12862-018-1230-1

Timoshkin O.A., Samsonov D.P., Yamamuro M. et al. 2016. Rapid ecological change in the coastal zone of Lake Baikal (East Siberia): is the site of the world's greatest freshwater biodiversity in danger? Journal of Great Lakes Research 42(3): 487-497. DOI: 10.1016/j.jglr.2016.02.011 